\title{
EFFECTS OF THE THICK WALLED PIPES WITH CONVECTIVE BOUNDARIES ON LAMINAR FLOW HEAT TRANSFER
}

\author{
Adekunle O. Adelaja ${ }^{1}$, Jaco Dirker ${ }^{2}$, Josua P. Meyer ${ }^{3}$ \\ ${ }^{1}$ Department of Mechanical and Aeronautical Engineering, University of Pretoria, Pretoria \\ Private Bag X20, Hatfield 0028, South Africa. \\ *Corresponding author: Tel: +27 717790790 Email: kunle.adelaja@up.ac.za \\ ${ }^{2}$ Department of Mechanical and Aeronautical Engineering, University of Pretoria, Pretoria, South Africa. \\ Email: jaco.dirker@up.ac.za \\ ${ }^{3}$ Department of Mechanical and Aeronautical Engineering, University of Pretoria, Pretoria, South Africa. \\ Email: josua.meyer@up.ac.za
}

\section{Highlights}

- Analytical approach is employed to solve the energy equations with convective boundary condition of the third kind.

- The wall thickness, $B i$ and $k_{p f}$ significantly influence the interfacial heat flux, the wall and fluid bulk temperatures.

- The fluid bulk and wall temperatures decrease with decreasing pipe wall thickness and increasing $B i$ number and $k_{p f}$.

- Increase in the convective heat loss corresponds to a decrease in wall thickness but increase in both $B i$ and $k_{p f}$.

- The thermal entrance length increases with pipe wall thickness while it decreases with increase in both $B i$ and $k_{p f}$.

\begin{abstract}
Conjugate heat transfer in laminar tube flow with convective boundary conditions is considered analytically. The steady state problem involving two-dimensional wall and axial fluid conduction is solved using separation of variables for a thick walled cylindrical pipe. The effects of the wall thickness, external Biot number and wall-tofluid thermal conductivity ratio are investigated on the heat flux, fluid bulk and wall temperatures. Results are presented for the cases when the wall thickness is between 0.1 and 2, Biot number ranging between 0.1 and 10 , and the ratio of wall-to-fluid thermal conductivity between 3 and 100. These parameters are found to significantly affect the heat transfer characteristics at the thermal entrance region, for instance, increase in wall thickness results in reduced heat flux while increase in Biot number and the ratio of the wall-to-fluid thermal conductivity result in increased heat flux. Decrease in wall thickness, increase in both Biot number and the ratio of the wall-to-fluid thermal conductivity correspond to decreased fluid bulk and wall temperature profiles.
\end{abstract}

Keywords: thick-walled pipe; Biot number; Peclet number; wall-to-fluid thermal conductivity ratio; convective heat transfer

\section{NONMENCLATURE}

Symbols

A Area $\left(\mathrm{m}^{2}\right)$

Bi Biot number

$C_{p} \quad$ Specific heat at constant pressure $\left(\mathrm{kJ} / \mathrm{kg} .{ }^{\circ} \mathrm{C}\right)$

$d \quad$ pipe diameter $(\mathrm{m})$

$G$ dimensionless function of axial position in fluid eq

$h \quad$ heat transfer coefficient $\left(\mathrm{W} / \mathrm{m}^{2} .{ }^{\circ} \mathrm{C}\right)$

$J_{0} \quad$ Bessel function of first kind, of zero order

$J_{l} \quad$ Bessel function of first kind, of unity order

$k$ thermal conductivity $\left(\mathrm{W} / \mathrm{m}^{\circ} \mathrm{C}\right)$

$L \quad$ characteristic length of system/ pipe (m)

$\mathrm{Nu} \quad$ Nusselt number, $h_{i} d_{i} / k_{f}$

$N u_{m} \quad$ Modified nusselt number, $U_{i} d_{i} / k_{f}$

$\mathrm{Pe} \quad$ Peclet number 

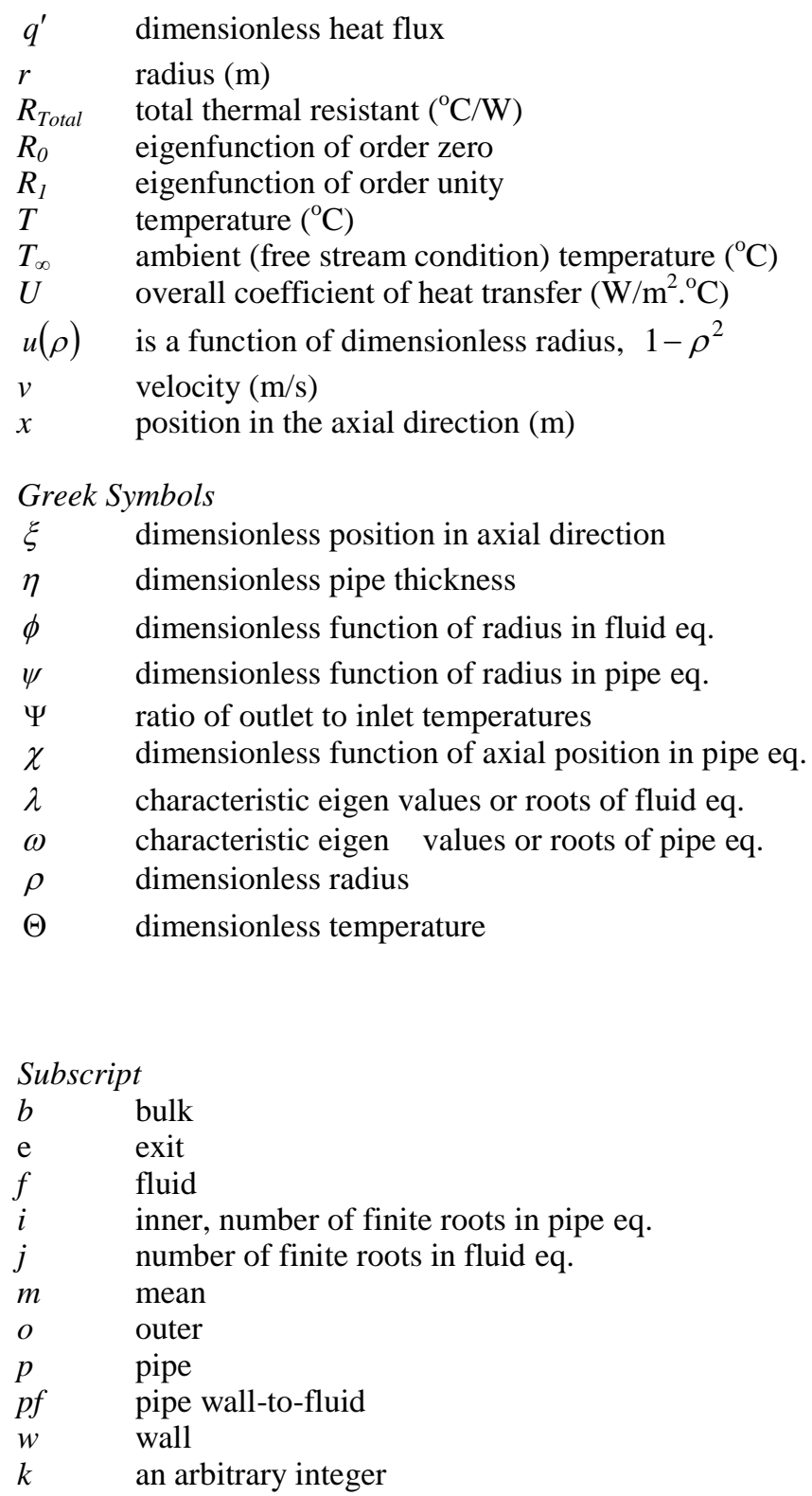

\section{INTRODUCTION}

Conjugate heat transfer in circular and rectangular ducts received considerable attention in the last century since the formulation of the Graetz problem. For the Graetz problem and subsequent studies, it was common practice to impose heat flux or temperature boundary conditions at the fluid-wall interface as well as neglect the duct wall conduction in the heat transfer process. In most realistic situations, the boundary conditions at the interface are not known initially but depend on the coupling between convection and conduction mechanisms at the interface [1]. It is the coupling between convection in the fluid and conduction in the duct that give the problem the name conjugate. This heat transfer problem is better analyzed by considering the simultaneous heat transfer inside the fluid and the wall. A comprehensive review of studies conducted on heat transfer in conventional ducts was carried out by Shah and London [2] and, Shah and Bhatti [3]. They concluded that wall conduction might have a significant effect on heat transfer especially in the thermal entrance region.

In earlier studies on conjugate heat transfer, various analytical and numerical solutions were employed to solve both the problems of thermal entrance region with axial conduction term and of fully developed flow. Most of these studies have also considered either prescribed heat flux or wall temperature boundary conditions. However, limited 
studies have been done on the problems of convective boundaries, that is, problems involving boundary conditions of the third kind [4-6].

Among the earlier studies on conjugate heat transfer are Mori et al. [7-8], who considered the effect of wall conduction between parallel plates and in circular pipes for uniform heat flux and constant surface temperature boundary conditions. The effect of axial wall conduction between parallel plates was analyzed for Couette flow by Davis and Gill [9]. Faghri and Sparrow [10] in their study on simultaneous wall and fluid axial conduction in laminar pipe flow proposed criteria for judging the importance of the axial heat conduction. Like Faghri and Sparrow, Zariffeh et al. [11] employed finite difference for their solution while Campo and Rangel [12] used analytical methods in their study of conjugate effect of one-dimensional fluid and wall axial conduction. In all these studies, extremely thin ducts were assumed.

With the emerging applications of heat transfer in micro-and mini-channels in micro-electro-mechanical systems (MEMS) - in which wall thickness of the duct or pipe is significant, it is however reasonable to view the problems of conjugate heat transfer as a two-dimensional wall (radial and axial) conduction. For this reason, a thick-walled duct is better used for this analysis. Before the emergence of micro tubes and channels though, some earlier researchers on conventional heat transfer in large tubes have extended their analysis to involve two-dimensional wall conduction. This found ready applications in high temperature, high pressure conveyance of fluid such as crude oil in the deep and ultra-deep offshore environment, etc. Pagiliarini [13] and Barozzi and Pagiliarini [14] investigated analytically, flows in thick-walled ducts/pipes with two-dimensional wall conduction. Campo and Shuler [15] employed lumped system to analyze the simultaneous wall and fluid axial conduction in laminar pipe flow heat transfer. Bilir [16] employed finite difference method to solve the combined effect of two-dimensional wall and fluid conductions for low Peclet number $(P e \leq 20)$ laminar flow. He considered a thick-walled two regional large cylindrical pipe with external constant temperature and a change at a given section. Chung and Sung [17] employed direct numerical simulation for turbulent flow in concentric annulus for $\operatorname{Re}=8900, \operatorname{Pr}=0.71$, radius ratio of 0.1 and 0.5 and heat flux ratio of $1: 10$. Results revealed that vortex regeneration between the inner and outer walls caused higher thermal structure at the outer walls. In the study of the effect of numerical simulations on the heat transfer of a fully developed turbulent pipe flow with isoflux on the wall for $R e=5500$, Redjem-Saad et al [18] observed that for $\operatorname{Pr} \geq 0.2$, temperature and turbulent heat flux increased with increasing $\operatorname{Pr}$. Esfahani and Shahabi [19] investigated the effect of heat flux distribution on entropy generation. The results indicated that heat flux distribution affected the extent of entropy generation and that it could be regulated by varying heat flux distribution or its rate of change. Tso et al [20] considered non-Newtonian fully developed laminar heat transfer in fluids between fixed parallel plates. The plates were maintained at different constant heat flux. The results showed that that the power indices of the fluids and the viscous dissipation affected the heat transfer. Ate et al [21] showed that wall thickness, wall-to-fluid thermal conductivity ratio, wall-to-fluid thermal diffusivity, Biot and Peclet numbers significantly influence the heat transfer characteristics in a thermally developing laminar flow in a two-dimensional wall and fluid conduction. The effect of the thickness of a trapezoidal wall placed between a heat source and a cold fluid was investigated on the hot spot temperature of the system [22]. ANSYS FLUENT 12.01 was used to optimize the thickness of the plate and it was shown that at the optimum thickness, the hot spot temperature decreased up to $25.06 \%$. For the six cases of non-uniform heat flux supplied to a circular pipe flow with Prandtl number of 13,400, Al-Maliky [23] reported an increase in Nusselt number (for known Prandtl number) and an increase in maximum velocity at the center of the fluid as Reynolds number increased. Furthermore, correlations were developed for each case.

For application to micro-tube, Zhang et al. [24] considered conjugate effect of two-dimensional wall conduction and fluid axial conduction for simultaneous developing laminar flow and heat transfer in microtube with varying dimensionless wall thickness and constant outer surface temperature. Results revealed that the heat transfer process was highly responsive to the wall-to-fluid conductivity ratio for the case when it was greater or equal to 25 . The role of the wall axial heat conduction was found to unify the inner wall surface heat flux. With axial conduction included in the convectional size ducts and the uncertainty in the friction factor associated with measurement error addressed in the micro-channels, the analysis of the convectional theory are adequate for micro channels [25-27].

In the present study, the combined effect of two-dimensional wall and fluid conduction is analyzed for low Peclet number $(P e=5)$ laminar flow heat transfer with convective boundary conditions of the third kind for the thermal entrance region problem. Both inner and outer wall surfaces of the circular pipe are subjected to convective heat transfer. Separation of variables method was employed to solve the conjugate problem for a circular pipe.

\section{PROBLEM FORMULATION}

The present study examines the effect of two-dimensional (radial and axial) wall and fluid heat conduction in a thick walled cylindrical pipe subjected to convective boundary conditions at both the inner and outer surfaces of the pipe. 
The fluid exchanges heat with the environment through the wall of the pipe with inner and outer radii $r_{i}$ and $r_{o}$ respectively. A single regional thick-wall pipe is considered as shown in Fig. 1.

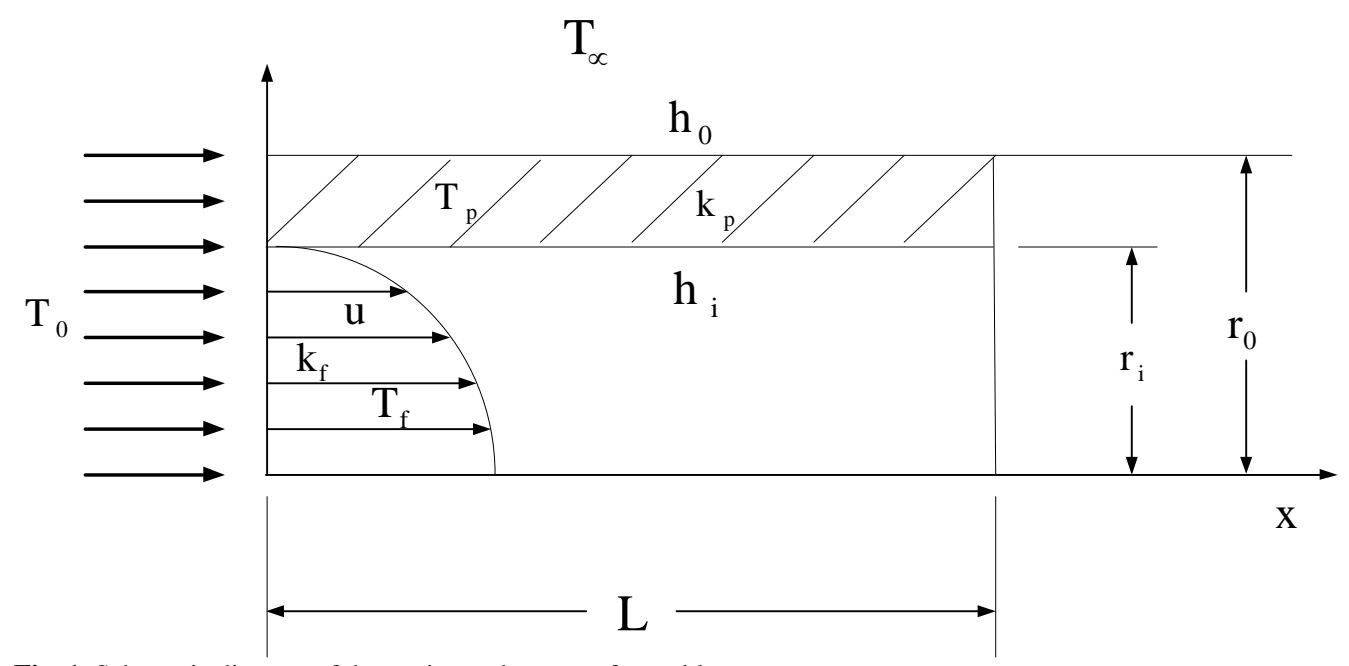

Fig. 1. Schematic diagram of the conjugate heat transfer problem.

The problem is analysed for low Peclet numbers $(P e=5)$ laminar flow. The fluid and wall are subjected to temperature $\left(T_{0}\right)$ at the entrance $(x=0)$. Heat flows from the fluid to the ambient through the pipe with heat transfer coefficient of $h_{i}$ at the inner surface and $h_{o}$ at the outer surface. The outlet fluid (at $\left.x=1\right)$ is at ambient temperature. The following assumptions were made: the fluid is Newtonian; viscous energy dissipation and internal heat energy generation are negligible. The physical properties of the fluid and pipe are constant. The heat transfer coefficients are also assumed constant along the surfaces. The study is rather focused on the temperatures and heat flux at the thermal entrance region for which the effect of axial fluid conduction is significant. This is important in engineering applications of flows with low Peclet numbers.

The dimensionless forms of the two-dimensional energy equations of the fluid and pipe are presented in the analysis below. On the fluid side, the differential equation is

$$
\frac{\partial \Theta_{f}(\rho, \xi)}{\partial \xi}=\frac{\partial^{2} \Theta_{f}(\rho, \xi)}{\partial \rho^{2}}+\frac{1}{\rho} \frac{\partial \Theta_{f}(\rho, \xi)}{\partial \rho}+\frac{1}{P e^{2}} \frac{\partial^{2} \Theta_{f}(\rho, \xi)}{\partial \xi^{2}}
$$

With boundary conditions

at $\xi=0 ; \quad \Theta_{f}(\rho, 0)=1$

at $\rho=0 ; \frac{\partial \Theta_{f}(0, \xi)}{\partial \rho}=0$

at $\rho=1 ; \quad \Theta_{f}(1, \xi)=\Theta_{p}(1, \xi)=\Theta_{w}(1, \xi)$

at $\rho=1 ; \frac{\partial \Theta_{f}(1, \xi)}{\partial \rho}+N u_{m} \Theta_{w}(1, \xi)=0$

where, $N u_{m}=\frac{U_{i} d_{i}}{k_{f}}, \quad U_{i}=\frac{1}{\sum R_{\text {Total }}}$ and

$\sum R_{\text {Total }}=\frac{1}{h_{i}}+\frac{A_{i} \ln \left(r_{o} / r_{i}\right)}{2 \pi k_{p} L}+\frac{A_{i}}{h_{O} A_{O}}$

On the pipe side, the differential equation is 
$\frac{\partial^{2} \Theta_{p}(\rho, \xi)}{\partial \rho^{2}}+\frac{1}{\rho} \frac{\partial \Theta_{p}(\rho, \xi)}{\partial \rho}+\frac{1}{P e^{2}} \frac{\partial^{2} \Theta_{p}(\rho, \xi)}{\partial \xi^{2}}=0$

With boundary conditions

at $\xi=0 ; \quad \Theta_{p}(\rho, 0)=1$

at $\rho=1 ; \Theta_{p}(1, \xi)=\Theta_{f}(1, \xi)$

at $\rho=1 ; \frac{\partial \Theta_{p}(1, \xi)}{\partial \rho}=\frac{1}{k_{p f}} \frac{\partial \Theta_{f}(1, \xi)}{\partial \rho}$

at $\rho=1+\eta ; \quad \frac{\partial \Theta_{p}(1+\eta, \xi)}{\partial \rho}+B i \Theta_{p}(1+\eta, \xi)=0$

The fluid bulk temperature, heat flux and Nusselt number may be calculated from

$\Theta_{b}=4 \int_{0}^{1} \rho\left(1-\rho^{2}\right) \Theta_{f} d \rho=0$

$q_{w}^{\prime}=\frac{\partial \Theta_{f}(1, \xi)}{\partial \rho}$

$N u=\frac{2 q_{w}^{\prime}}{\Theta_{b}-\Theta_{w i}}$

The dimensionless parameters of the problem are defined as

$\Theta_{f}=\frac{T(\rho, \xi)-T_{\infty}}{T_{0}(\rho, 0)-T_{\infty}} ; \quad \rho=\frac{r}{r_{i}} ; \quad \xi=\frac{x}{r_{i} P e} ; \quad P e=\operatorname{Re} * \operatorname{Pr}=\frac{2 v_{m} r_{i} \rho_{f} c_{p f}}{k_{f}} ; \quad k_{p f}=\frac{k_{p}}{k_{f}} ; \quad \eta=\frac{r_{O}-r_{i}}{r_{i}} ;$

$B i=\frac{h_{O} r_{O}}{k_{p}}$

In dimensionless form, the modified Nusselt number can be expressed as [25]

$N u_{m}=\frac{\operatorname{Re} \cdot \operatorname{Pr} \cdot k_{p f} \ln \Psi}{2 \cdot L^{*} \cdot k_{p f}+\operatorname{Re} \cdot \operatorname{Pr} \ln \Psi\left(\ln D^{*}+\frac{1}{B i}\right)}$

where, $\Psi=\frac{T_{e}(\rho, 1)-T_{\infty}}{T_{0}(\rho, 0)-T_{\infty}}, \quad D^{*}=\frac{d_{o}}{d_{i}}, \quad L^{*}=\frac{L}{d_{i}}$

\subsection{Analysis of Problem}

The solution of the problem defined by eq. (1) and eq. (3) are obtained analytically via the separation of variables method subject to the boundary conditions eqs. (2a-d) and eqs. (4a-d) respectively. The fluid temperature is decomposed into both the radial $\rho$ and axial $\xi$ components

$\Theta_{f}(\rho, \xi)=\phi_{j}(\rho) G_{j}(\xi)$

Introducing eq. (8) into eq. (1) gives two separate differential equations for the axial and radial components as eq. (9) and eq. (10) respectively

$u(\rho) \frac{d G_{j}}{d \xi}-\frac{1}{P e^{2}} \frac{d^{2} G_{j}}{d \xi^{2}}+\lambda_{j}^{2} u(\rho) G_{j}=0$

and 
$\frac{d}{d \rho}\left(\rho \frac{d \phi_{j}}{d \rho}\right)+\rho \lambda_{j}^{2} u(\rho) \phi_{j}=0$

where, $u(\rho)=\left(1-\rho^{2}\right)$ and $\lambda_{j}$ are the eigenvalues of the solution of eq. (1). The solution of eq. (9) takes the form of eq. (11) for a finite solution of $G_{j}(\xi)$

$G_{j}(\xi)=c_{1 j} e^{-\lambda^{2} \xi}$

where, $c_{1 j}$ are arbitrary constants. Eq. (10) is satisfied by the following Bessel solution

$\phi_{j}=\sum_{j}^{\infty} D_{j} J_{0}\left(\lambda_{j} \rho\right)$

where $D_{j}$ are constants. Introducing eq. (11) and eq. (12) into eq. (8) gives

$\Theta_{f}(\rho, \xi)=\sum_{j}^{\infty} c_{j} J_{0}\left(\lambda_{j} \rho\right) e^{-\lambda_{j}^{2} \xi}$

where, the coefficients $c_{j}=c_{1 j} D_{j}$.

Inserting eq. (13) into eq. (2b) and simplifying gives

$J_{1}(0)=0$

Substituting eq. (13) into eqs. (2c \& d) and after some simplifications give

$\frac{d}{d \rho} \sum_{j}^{\infty} c_{j} J_{0}\left(\lambda_{j} \rho\right) e^{-\lambda_{j}^{2} \xi}=-N u_{m} \sum_{j}^{\infty} c_{j} J_{0}\left(\lambda_{j} \rho\right) e^{-\lambda_{j}^{2} \xi}$

After some manipulations, eq. (15) gives

$J_{0}^{\prime}\left(\lambda_{j}\right)=-N u_{m} J_{0}\left(\lambda_{j}\right)$

which can also be written as

$J_{1}\left(\lambda_{j}\right)=\frac{N u_{m} J_{0}\left(\lambda_{j}\right)}{\lambda_{j}}$

Constants $c_{j}$ in eq. (13) can be obtained by using the boundary condition (2a) and evaluating for orthogonality at $\xi=0$

$\Theta_{f}(\rho, 0)=\sum_{j}^{\infty} c_{j} J_{0}\left(\lambda_{j} \rho\right)=1$

Multiplying both sides of eq. (17a) by $g(\rho) J_{0}\left(\lambda_{k} \rho\right)$ and integrating both sides over $\rho$ between zero and unity $(0,1)$ give eq. (17b) where $g(\rho)$ is the weighted function and it is defined as $g(\rho)=\rho u(\rho)=\rho\left(1-\rho^{2}\right)$.

$\sum_{j}^{\infty} c_{j} \int_{0}^{1} \rho\left(1-\rho^{2}\right) J_{0}\left(\lambda_{j} \rho\right) J_{0}\left(\lambda_{k} \rho\right) d \rho=\int_{0}^{1} \rho\left(1-\rho^{2}\right) J_{0}\left(\lambda_{k} \rho\right) d \rho$

After the operation, the left hand side of eq. (17b) can be expressed as

$\sum_{j}^{\infty} c_{j} \int_{0}^{1} \rho\left(1-\rho^{2}\right) J_{0}\left(\lambda_{j} \rho\right) J_{0}\left(\lambda_{k} \rho\right) d \rho= \begin{cases}0, & j \neq k \\ \text { Number } & j=k\end{cases}$

while, the right hand side of the eq. (17b) can be further simplified as

$\int_{0}^{1} \rho\left(1-\rho^{2}\right) J_{0}\left(\lambda_{k} \rho\right) d \rho=-\frac{J_{0}^{\prime}\left(\lambda_{j}\right)}{\lambda_{j}^{2}}$

The coefficients $c_{j}$ can be evaluated when $j=k$ as 
$c_{j}=\frac{\int_{0}^{1} \rho\left(1-\rho^{2}\right) J_{0}\left(\lambda_{j} \rho\right) d \rho}{\int_{0}^{1} \rho\left(1-\rho^{2}\right) J_{0}^{2}\left(\lambda_{j} \rho\right) d \rho}$

Inserting the solution of eq. (18) and eq. (19) into eq. (20) and evaluating the result gives the coefficients as $c_{j}=-\frac{J_{0}^{\prime}\left(\lambda_{j}\right)}{\frac{\lambda_{j}^{2}}{3}\left(J_{0}^{2}\left(\lambda_{j}\right)+J_{1}^{2}\left(\lambda_{j}\right)+\frac{1}{\lambda_{j}^{2}}\left(J_{1}^{2}\left(\lambda_{j}\right)-\lambda_{j} J_{0}\left(\lambda_{j}\right) J_{1}\left(\lambda_{j}\right)\right)\right)}$

Introducing eq. (16a) into eq. (21) and after some manipulations leads to

$$
c_{j}=\frac{3 N u_{m}}{\lambda_{j}^{2}\left(\left(1+N u_{m}^{2}\right)+\frac{1}{\lambda_{j}^{2}}\left(N u_{m}^{2}+N u_{m}\right)\right) J_{0}\left(\lambda_{j}\right)}
$$

Finally, the fluid temperature is obtained when eq. (22) is introduced into eq. (13)

$$
\Theta_{f}(\rho, \xi)=3 N u_{m} \sum_{j=1}^{\infty} \frac{J_{0}\left(\lambda_{j} \rho\right) e^{-\lambda_{j}^{2} \xi}}{\lambda_{j}^{2}\left(\left(1+N u_{m}^{2}\right)+\frac{1}{\lambda_{j}^{2}}\left(N u_{m}^{2}+N u_{m}\right)\right) J_{0}\left(\lambda_{j}\right)}
$$

To calculate the bulk temperature, eq. (23) is introduced into eq. (5) and integrated between the limits $(0,1)$ which leads to

$$
\Theta_{b}(\rho, \xi)=12 N u_{m}^{2} \sum_{j=1}^{\infty} \frac{e^{-\lambda_{j}^{2} \xi}}{\lambda_{j}^{4}\left(\left(1+N u_{m}^{2}\right)+\frac{1}{\lambda_{j}^{2}}\left(N u_{m}^{2}+N u_{m}\right)\right)}
$$

From eq. (3), the solution of the pipe equation can be decomposed into both the radial and axial components thus $\Theta_{p}(\rho, \xi)=\psi_{i}(\rho) \chi_{i}(\xi)$

Introducing eq. (25) into eq. (3) and separating into both axial (eq. 26) and radial (eq. 27) components as

$$
\begin{aligned}
& \frac{d^{2} \chi_{i}}{d \xi^{2}}-P e^{2} \omega_{i}^{2} \chi_{i}(\xi)=0 \\
& \frac{d}{d \rho}\left(\rho \frac{d \psi_{i}}{d \rho}\right)+\rho \omega_{i}^{2} \psi_{i}=0
\end{aligned}
$$

where $\omega_{i}$ are the eigenvalues of the solution of eq. (3). The solution of eq. (26) for a finite pipe temperature profile can be expressed as

$\chi_{i}(\xi)=a_{1 i} e^{-P e \omega_{i} \xi}$

where, $a_{1 i}$ are constants. Eq. (27) is satisfied by the Bessel solution specified as

$\psi_{i}(\rho)=\sum_{i}^{\infty} M_{i} R_{0}\left(\omega_{i} \rho\right)$

where $M_{i}$ are arbitrary constants. Therefore, the solution of eq. (3) is given in the form

$\Theta_{p}(\rho, \xi)=\sum_{i}^{\infty} F_{i} R_{0}\left(\omega_{i}, \rho\right) e^{-P e \omega_{i} \xi}$

where the expansion coefficients $F_{i}=a_{1 i} M_{i}$ 
Substitute eq. (30) into eq. (4b) and evaluating the result at the boundary condition gives

$\sum_{i}^{\infty} F_{i} R_{0}^{\prime}\left(\omega_{i}, 1\right) e^{-P e \omega_{i} \xi}=\sum_{j}^{\infty} c_{j} J_{0}^{\prime}\left(\lambda_{j}\right) e^{-\lambda_{j}^{2} \xi}$

Eq. (13) and eq. (30) are introduced into eq. (4c) to give

$\sum_{i}^{\infty} F_{i} R_{0}\left(\omega_{i}, 1\right) e^{-P e \omega_{i} \xi}=\frac{1}{k_{p f}} \sum_{j}^{\infty} c_{j} J_{0}\left(\lambda_{j}\right) e^{-\lambda_{j}^{2} \xi}$

Eqs. $(31 \mathrm{a}, \mathrm{b})$ are simplified to give

$R_{0}^{\prime}\left(\omega_{i}, 1\right)=\frac{J_{0}^{\prime}\left(\lambda_{j}\right) R_{0}\left(\omega_{i}, 1\right)}{{ }_{p f} J_{0}\left(\lambda_{j}\right)}$

On introducing eq. (30) into eq. (4d) and simplifying results in

$R_{0}^{\prime}\left(\omega_{i}, 1+\eta\right)=-B i R_{0}\left(\omega_{i}, 1+\eta\right)$

After inserting eq. (30) into eq. (4a) leads to

$\Theta_{p}(\rho, 0)=\sum_{i}^{\infty} F_{i} R_{0}\left(\omega_{i}, \rho\right)=1$

It is obvious that the $F_{i}$ in eq. (34) can be obtained by multiplying both sides of eq. (34) by $R_{0}\left(\omega_{k} \rho\right)$ and integrating between 1 and $1+\eta$ i.e. $(1,1+\eta)$ where $\rho$ is the weighted function given in

$\sum_{1}^{\infty} F_{i} \int_{1}^{1+\eta} \rho R_{0}\left(\omega_{i}, \rho\right) R_{0}\left(\omega_{k}, \rho\right) d \rho=\int_{1}^{1+\eta} \rho R_{0}\left(\omega_{k}, \rho\right) d \rho$

The right hand side of eq. (35) only has a value when $i=k$, therefore the coefficients of the pipe solution, $F_{i}$ are obtained as follows

$F_{i}=\frac{\int_{1}^{1+\eta} \rho R_{0}\left(\omega_{i}, \rho\right) d \rho}{\int_{1}^{1+\eta} \rho R_{0}^{2}\left(\omega_{i}, \rho\right) d \rho}$

To obtain the numerator, introducing eq. (30) into eq. (27) and rearranging the resulting equation leads to

$\rho R_{0}\left(\omega_{i}, \rho\right)=-\frac{1}{\omega_{i}^{2}} \frac{d}{d \rho}\left(\rho \frac{d}{d \rho} R_{0}\left(\omega_{i}, \rho\right)\right)$

Integrating both sides of eq. (37) now gives

$\int_{1}^{1+\eta} \rho R_{0}\left(\omega_{i}, \rho\right) d \rho=-\frac{1}{\omega_{i}^{2}}\left((1+\eta) R_{0}^{\prime}\left(\omega_{i}, 1+\eta\right)-R_{0}^{\prime}\left(\omega_{i}, 1\right)\right)$

Note that the denominator of eq. (36) can be expressed as

$\int_{1}^{1+\eta} \rho R_{0}^{2}\left(\omega_{i}, \rho\right) d \rho=\frac{1}{2}\left((1+\eta)^{2}\left(R_{0}^{2}\left(\omega_{i}, 1+\eta\right)+R_{0}^{\prime 2}\left(\omega_{i}, 1+\eta\right)\right)-\left(R_{0}^{2}\left(\omega_{i}, 1\right)+R_{0}^{\prime 2}\left(\omega_{i}, 1\right)\right)\right)$

Introducing eq. (38) and eq. (39) into eq. (36) enables the expansion coefficient $F_{i}$ to be calculated as

$$
F_{i}=\frac{-\frac{1}{\omega_{i}^{2}}\left((1+\eta) R_{0}^{\prime}\left(\omega_{i}, 1+\eta\right)-R_{0}^{\prime}\left(\omega_{i}, 1\right)\right)}{\frac{1}{2}\left((1+\eta)^{2}\left(R_{0}^{2}\left(\omega_{i}, 1+\eta\right)+R_{0}^{\prime 2}\left(\omega_{i}, 1+\eta\right)\right)-\left(R_{0}^{2}\left(\omega_{i}, 1\right)+R_{0}^{\prime 2}\left(\omega_{i}, 1\right)\right)\right)}
$$

Knowing the coefficients eq. (40) can then be inserted into eq. (30) to obtain the temperature profile for the pipe $\Theta_{p}=-2 \sum_{i=1}^{\infty} \frac{\left((1+\eta) R_{0}^{\prime}\left(\omega_{i}, 1+\eta\right)-R_{0}^{\prime}\left(\omega_{i}, 1\right)\right) R_{0}\left(\omega_{i}, \rho\right) e^{-P e \omega_{i} \xi}}{\left((1+\eta)^{2}\left(R_{0}^{2}\left(\omega_{i}, 1+\eta\right)+R_{0}^{\prime 2}\left(\omega_{i}, 1+\eta\right)\right)-\left(R_{0}^{2}\left(\omega_{i}, 1\right)+R_{0}^{\prime 2}\left(\omega_{i}, 1\right)\right)\right)}$

Eq. (42) is obtained by introducing eq. (32) and eq. (33) into eq. (41)

$\Theta_{p}=2 \sum_{i=1}^{\infty} \frac{\left((1+\eta) B i R_{0}\left(\omega_{i}, 1+\eta\right)-\frac{N u_{m}}{k_{p f}} R_{0}\left(\omega_{i}, 1\right)\right) R_{0}\left(\omega_{i}, \rho\right) e^{-P e \omega_{i} \xi}}{\omega_{i}^{2}\left((1+\eta)^{2}\left(1+B i^{2}\right) R_{0}^{2}\left(\omega_{i}, 1+\eta\right)-\left(1+\left(\frac{N u_{m}}{k_{p f}}\right)^{2}\right) R_{0}^{2}\left(\omega_{i}, 1\right)\right)}$

where 
$R_{0}\left(\omega_{i}, \rho\right)=\left(\frac{J_{0}\left(\omega_{i} \rho\right)}{\omega_{i} J_{0}^{\prime}\left(\omega_{i} 1+\eta\right)+\frac{B i}{1+\eta} J_{0}\left(\omega_{i} 1+\eta\right)}-\frac{Y_{0}\left(\omega_{i} \rho\right)}{\omega_{i} Y_{0}^{\prime}\left(\omega_{i} 1+\eta\right)+\frac{B i}{1+\eta} Y_{0}\left(\omega_{i} 1+\eta\right)}\right) \frac{1}{k_{p}}$

The dimensionless form of the eigen values/ roots for the pipe temperature solution can be adapted from Ozisik [28] as

$$
\frac{\omega_{i} J_{0}^{\prime}\left(\omega_{i} 1\right)+N u_{m} J_{0}\left(\omega_{i} 1\right)}{\omega_{i} J_{0}^{\prime}\left(\omega_{i} 1+\eta\right)+\frac{B i}{1+\eta} J_{0}\left(\omega_{i} 1+\eta\right)}-\frac{\omega_{i} Y_{0}^{\prime}\left(\omega_{i} 1\right)+N u_{m} Y_{0}\left(\omega_{i} 1\right)}{\omega_{i} Y_{0}^{\prime}\left(\omega_{i} 1+\eta\right)+\frac{B i}{1+\eta} Y_{0}\left(\omega_{i} 1+\eta\right)}=0
$$

\subsection{RESULTS AND DISCUSSION}

Presented in this paper are the results of the study of the effects of pipe wall thickness $\eta$, Biot number $B i$ and, the ratio of wall-to-fluid thermal conductivity $k_{p f}$ on the bulk and wall temperatures and, heat flux in a laminar flow for a thick-walled pipe subjected to convective boundaries at both the inner and outer surfaces of the pipe at the thermal entry region. The study was conducted for low $P e$ of $5, L^{*}=8, B i$ ranging between 0.1 and $10, k_{p f}$ between 3 and 100 and wall thickness between 0.1 and 2 . Using the range of parameters mentioned earlier, the results were simulated in MATLAB 2010a environment. The $x$-axis in the results was ranged between 0.0 and 0.5 to enable clear views of the profiles.

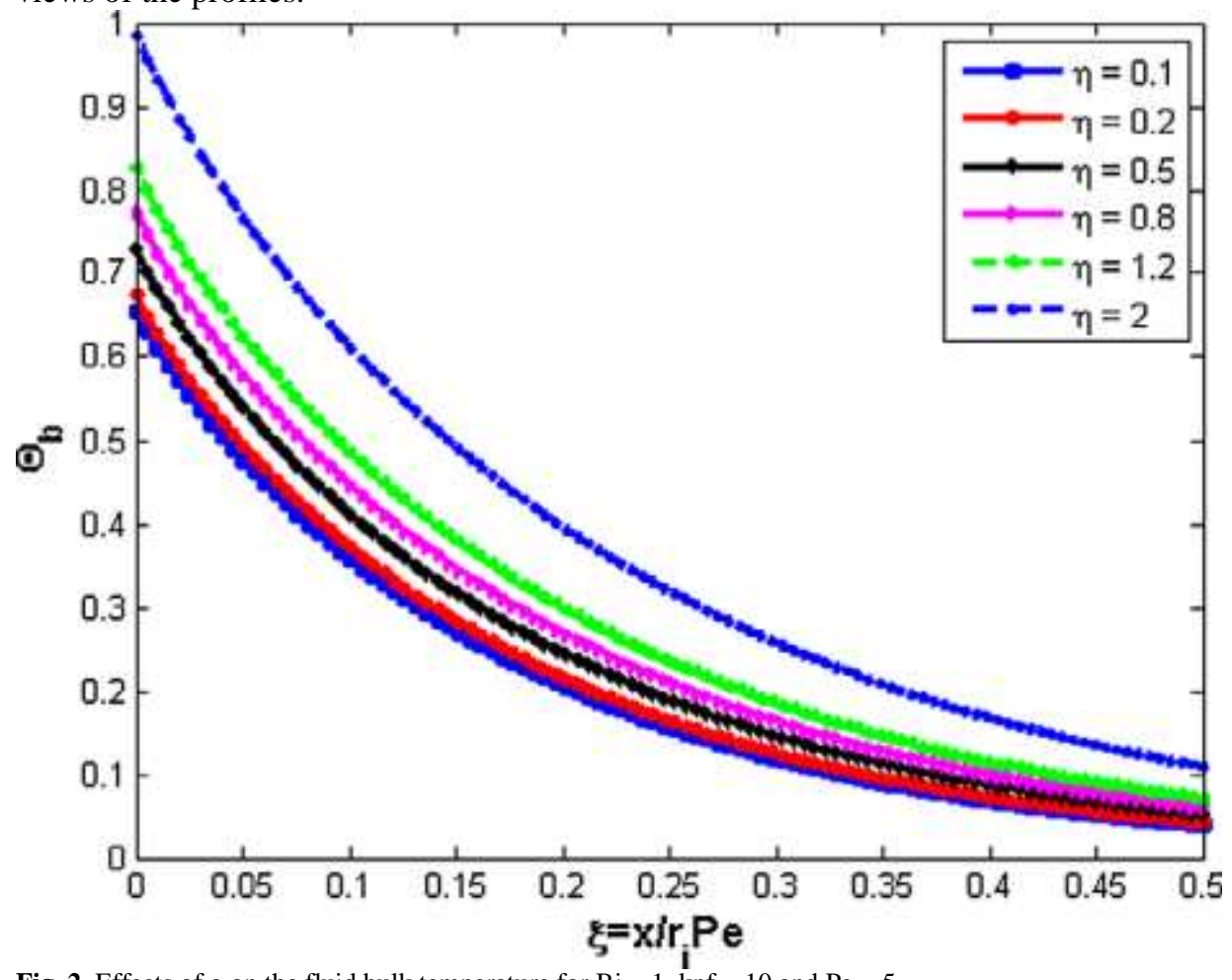

Fig. 2. Effects of $\mathrm{g}$ on the fluid bulk temperature for $\mathrm{Bi}=1, \mathrm{kpf}=10$ and $\mathrm{Pe}=5$.

Fig. 2 to Fig. 4 reveal the effect of the variables under consideration on the fluid bulk temperature. Fig. 2 shows the effect of $\eta$ on $\Theta_{b}$ for $B i=1, k_{p f}=10, P e=5$ and $L^{*}=8$. The result shows that the smaller the thickness of the pipe wall, the greater the conduction from the fluid across the pipe wall to the environment. That is, increase in wall thickness increases the wall thermal resistance to heat transfer between the fluid and the environment, hence, less heat flow leading to a higher temperature profile in a thicker pipe. In Fig. 3, the effect of external $B i$ on $\Theta_{b}$ is investigated for $k_{p f}=10, P e=5$ and $\eta=0.5$. Increase in $B i$ indicates an increase in the convective heat transfer at the external surface of the pipe. The result shows that there is a general decrease in $\Theta_{b}$ with increasing $B i$. The effect of $B i$ on $\Theta_{b}$ decreases as it $(B i)$ increases. Fig. 4 presents the effect of $k_{p f}$ on $\Theta_{b}$ for $P e=5, B i=1$, and $\eta=0.5$. Large $k_{p f}$ corresponds to the case where there is negligible wall resistance as in the case of low conductivity fluid in a metal 


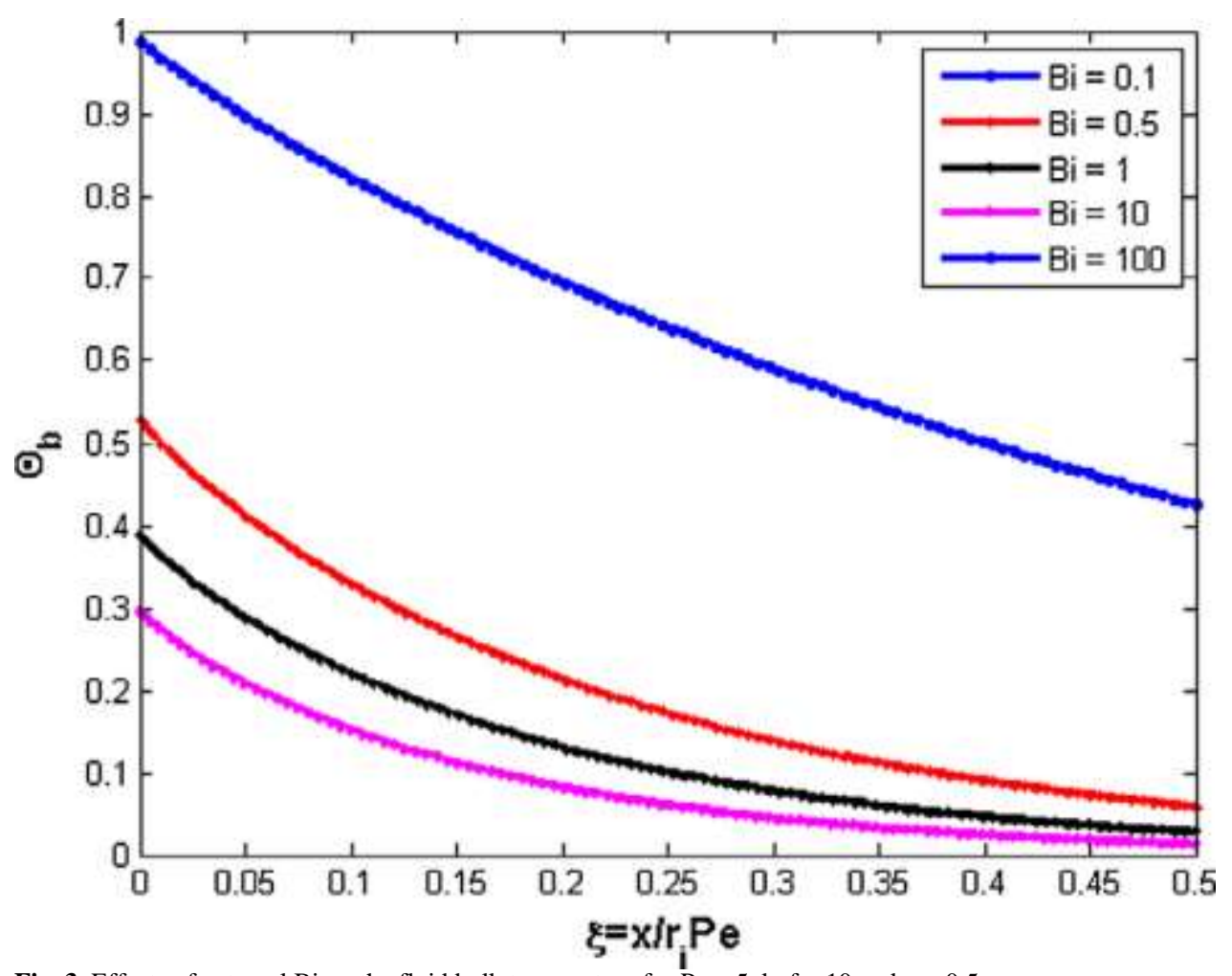

Fig. 3. Effects of external $\mathrm{Bi}$ on the fluid bulk temperature for $\mathrm{Pe}=5, \mathrm{kpf}=10$ and $\mathrm{g}=0.5$.

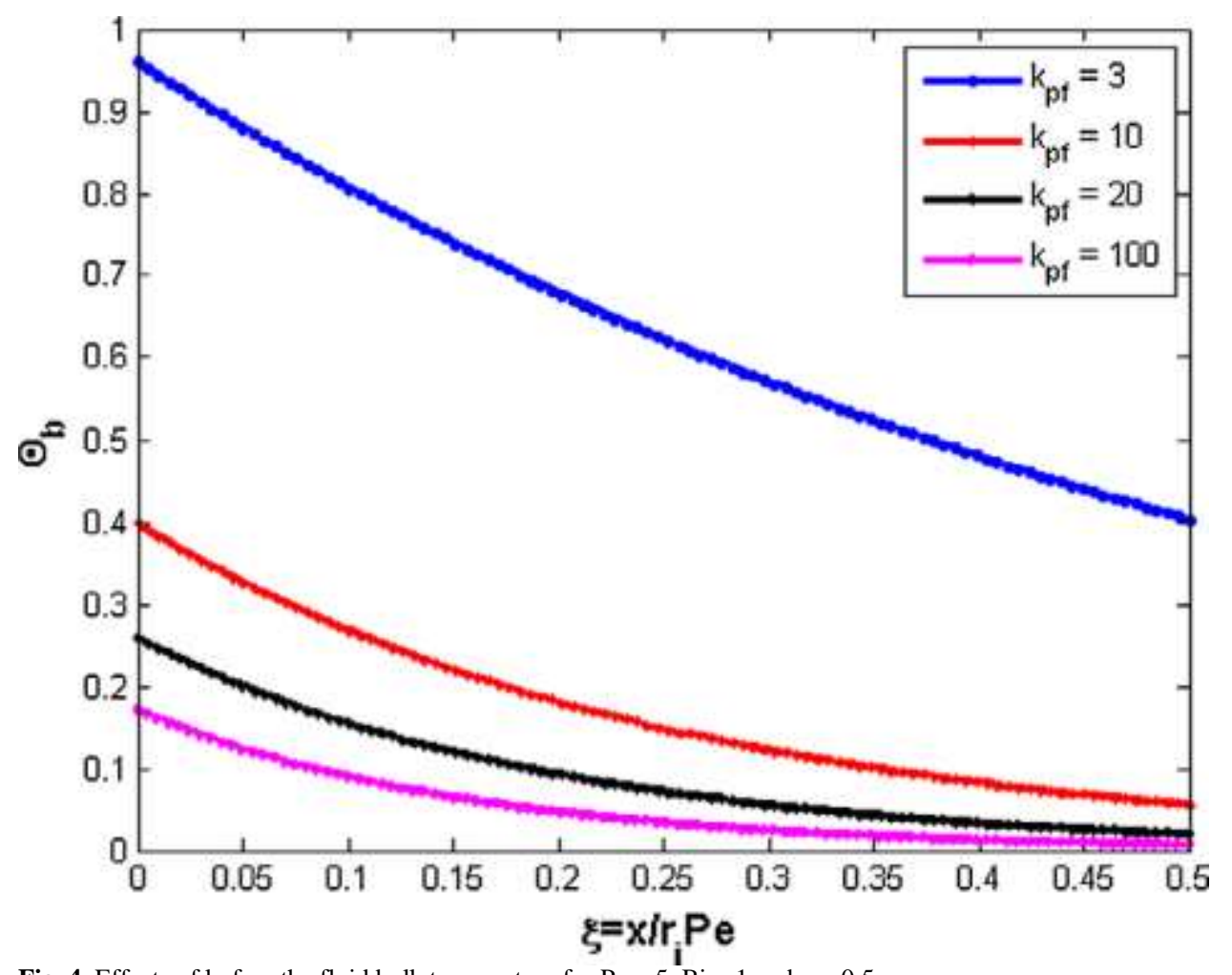

Fig. 4. Effects of kpf on the fluid bulk temperature for $\mathrm{Pe}=5, \mathrm{Bi}=1$ and $\mathrm{g}=0.5$.

pipe or for a very high thermal conductive pipe. For this case, the rate of heat transfer by conduction from the fluid is high. For high fluid thermal conductivity as in liquid metal $k_{p f}$ is small thus, the resistance of wall radial heat 


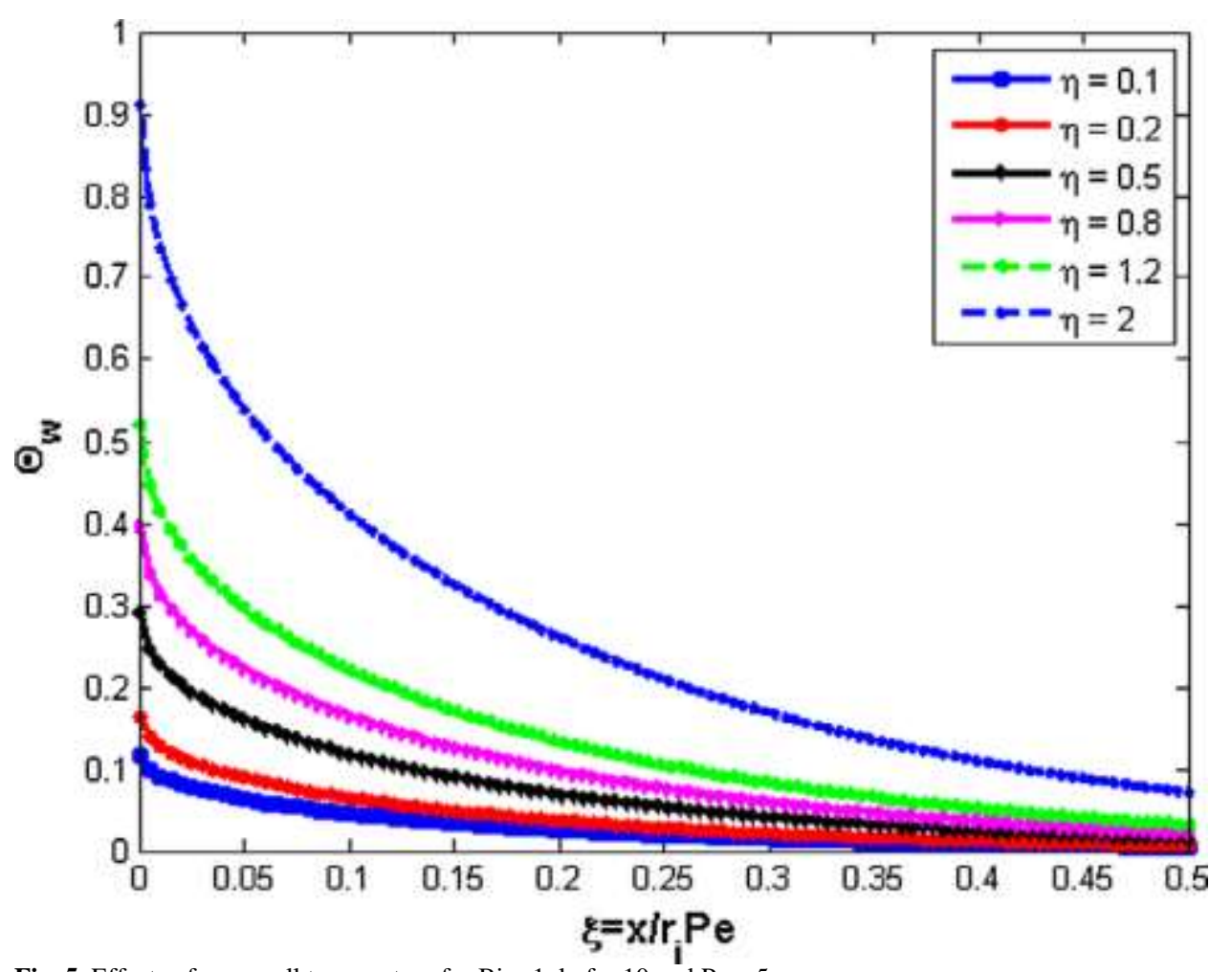

Fig. 5. Effects of $\mathrm{g}$ on wall temperature for $\mathrm{Bi}=1, \mathrm{kpf}=10$ and $\mathrm{Pe}=5$.

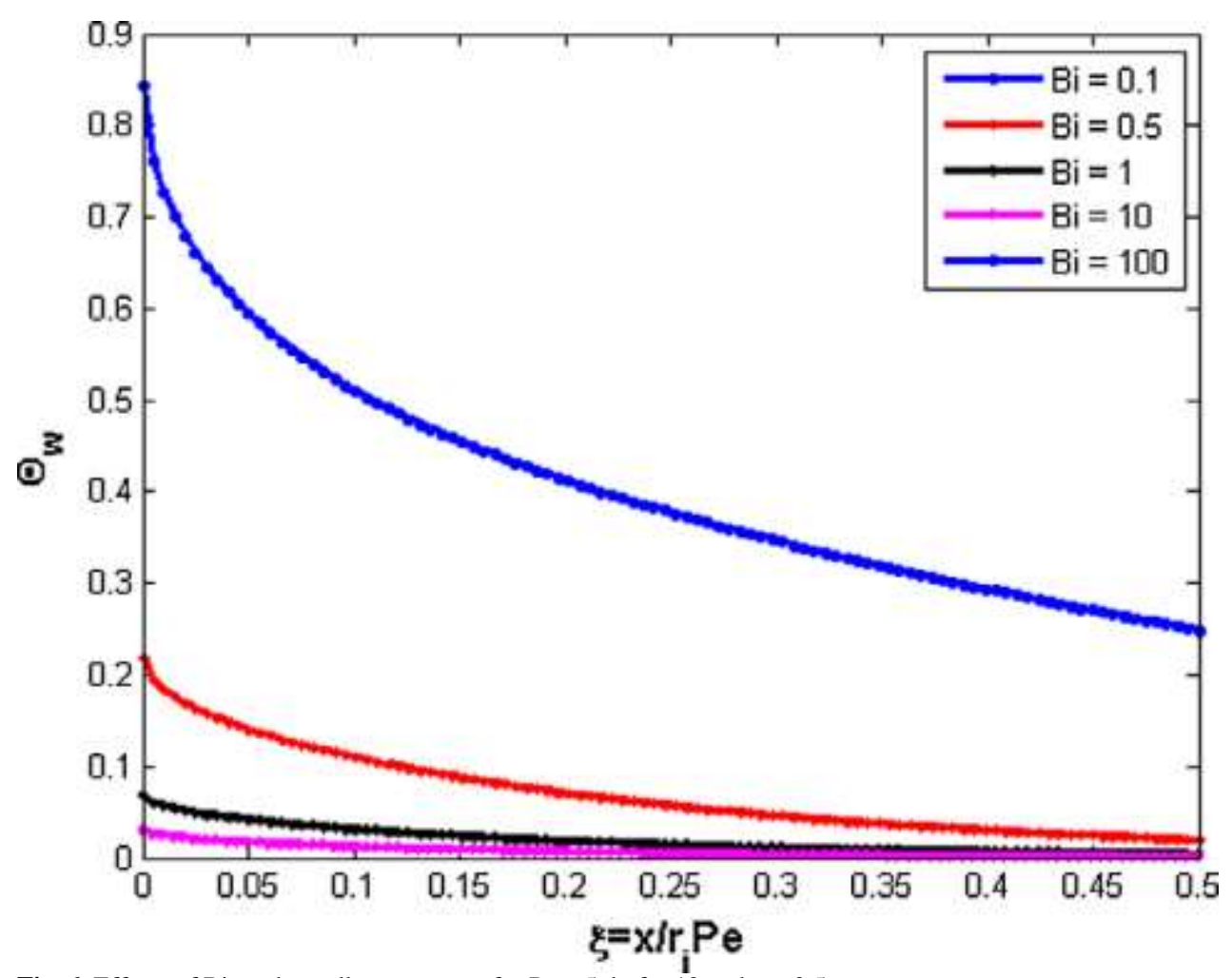

Fig. 6. Effects of $\mathrm{Bi}$ on the wall temperature for $\mathrm{Pe}=5, \mathrm{kpf}=10$ and $\mathrm{g}=0.5$. 


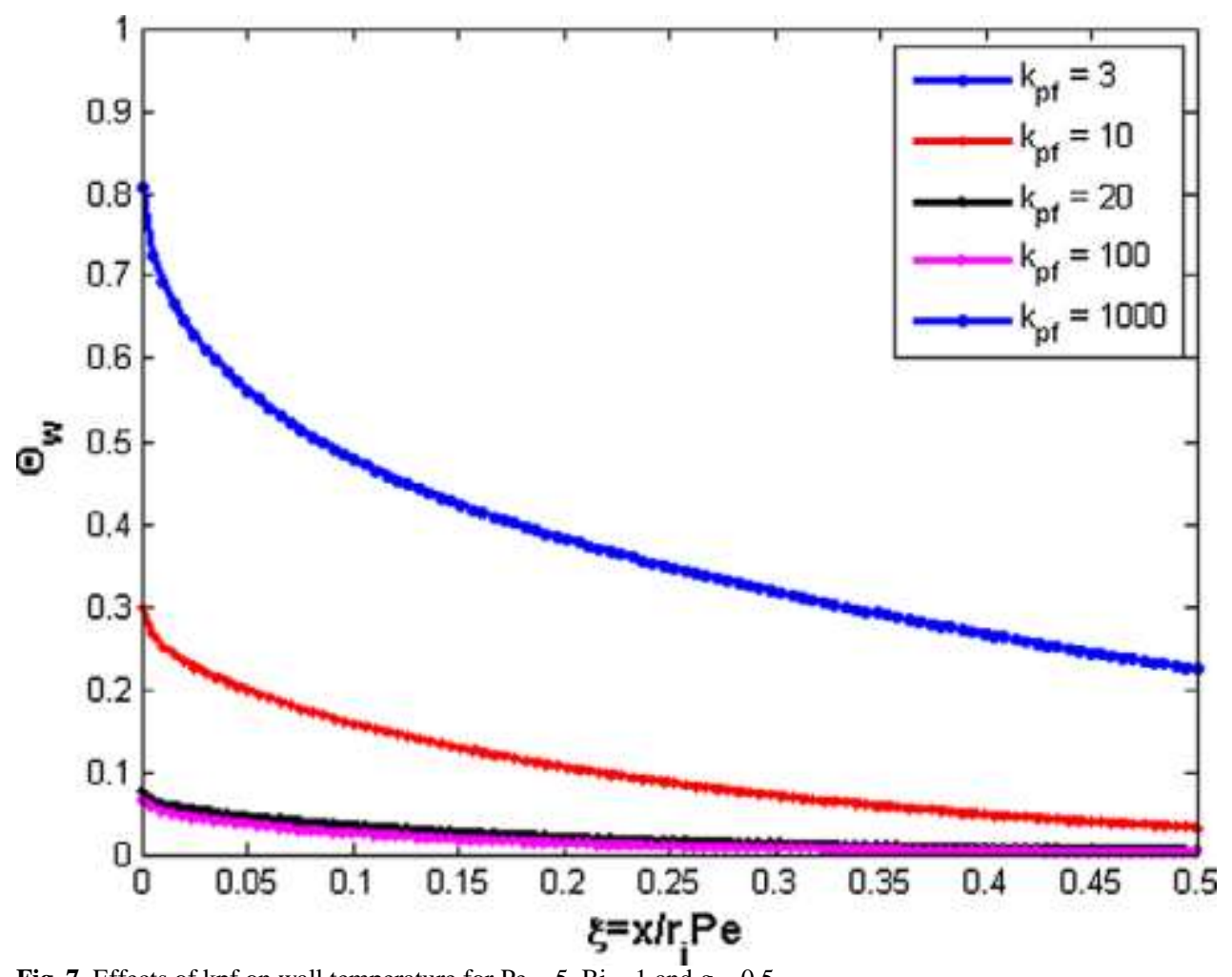

Fig. 7. Effects of kpf on wall temperature for $\mathrm{Pe}=5, \mathrm{Bi}=1$ and $\mathrm{g}=0.5$.

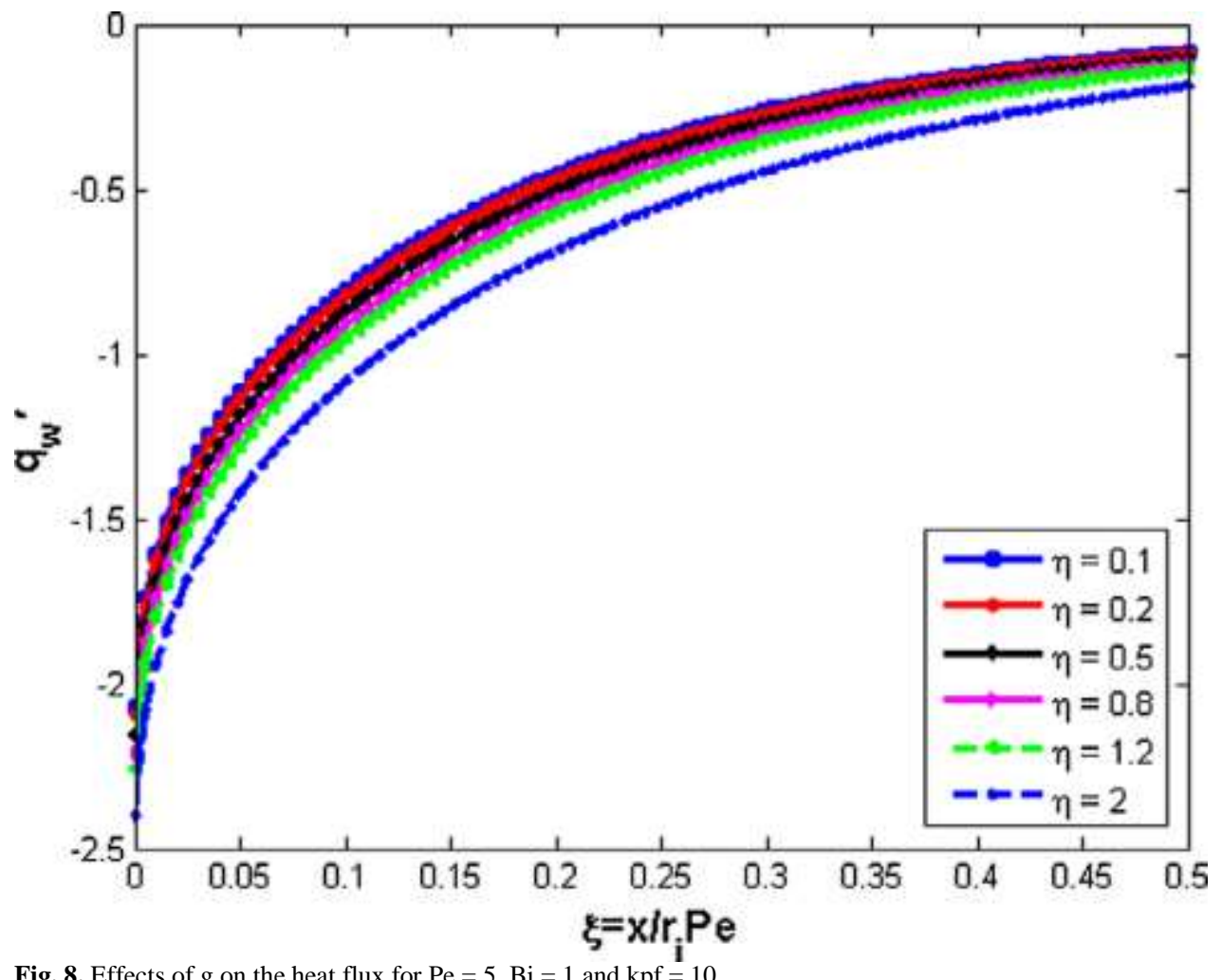

Fig. 8. Effects of $\mathrm{g}$ on the heat flux for $\mathrm{Pe}=5, \mathrm{Bi}=1$ and $\mathrm{kpf}=10$. 


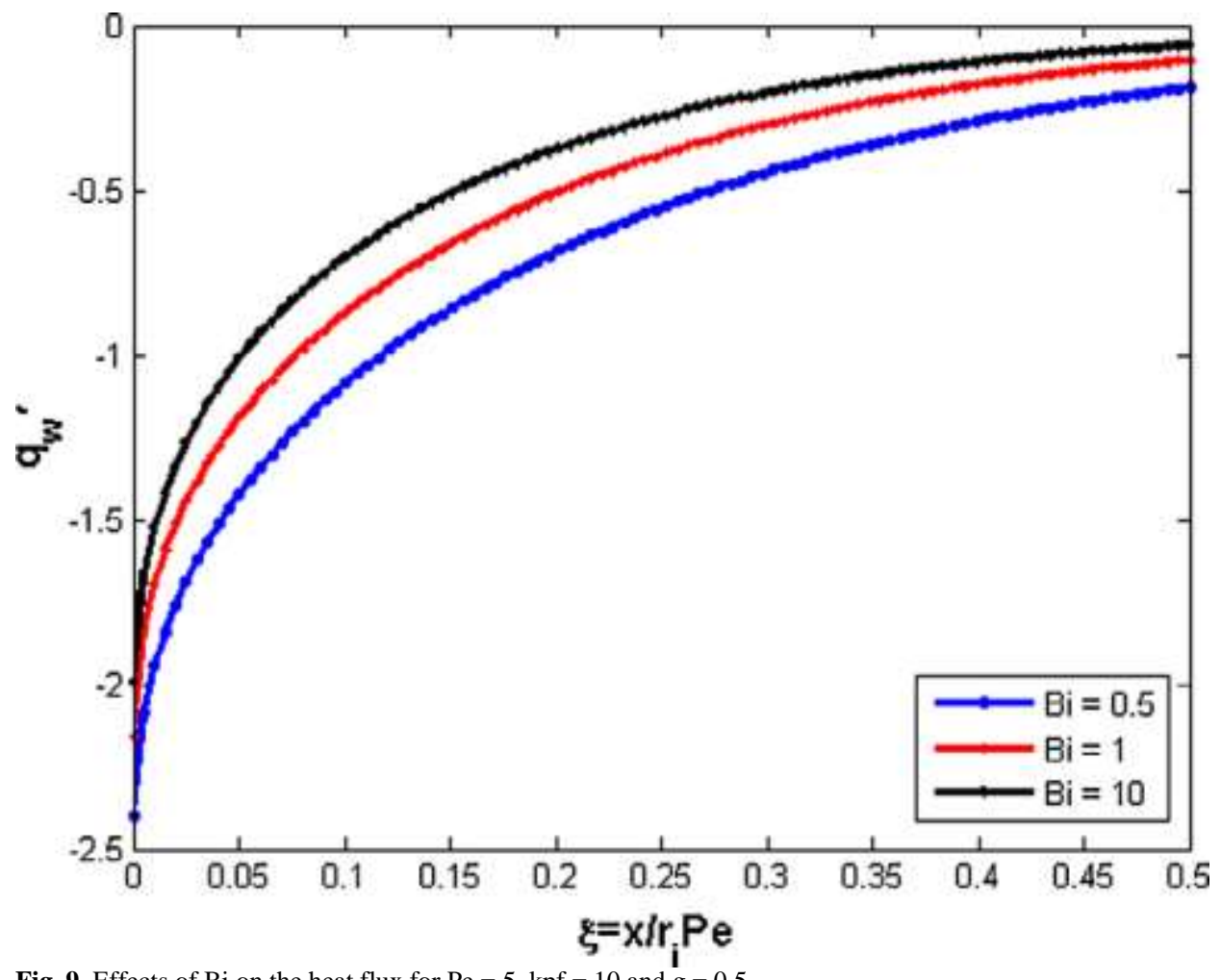

Fig. 9. Effects of $\mathrm{Bi}$ on the heat flux for $\mathrm{Pe}=5, \mathrm{kpf}=10$ and $\mathrm{g}=0.5$.

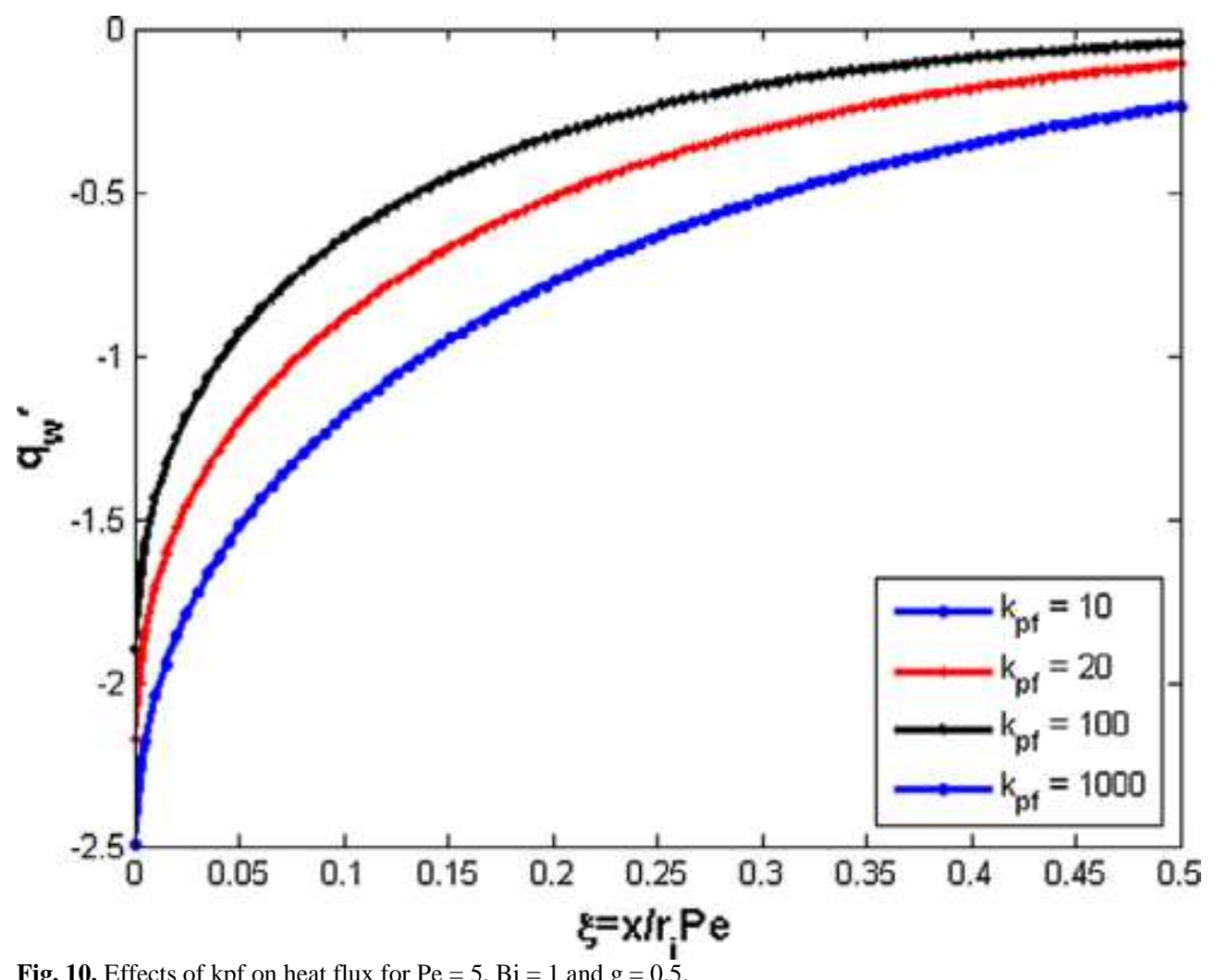

Fig. 10. Effects of kpf on heat flux for $\mathrm{Pe}=5, \mathrm{Bi}=1$ and $\mathrm{g}=0.5$. 
conduction is not negligible. The result reveals that $\Theta_{b}$ decreases with increasing $k_{p f}$. Large value of $k_{p f}$ means that the fluid, through pipe wall conduction, loses more heat and so the temperature of the fluid drops as $k_{p f}$ increases. It can also be seen that the thermal entrance length becomes smaller as $k_{p f}$ increases.

On the wall temperature, the effect of $\eta, B i$ and $k_{p f}$ are investigated on $\Theta_{w}$ for the same conditions as considered in the case of $\Theta_{b}$. Fig. 5 displays the effect of $\eta$ on $\Theta_{w}$ for $B i=1, k_{p f}=10, P e=5, L^{*}=8$ and $\eta=0.5$. Similar to Fig. 2, the result reveals that increase in $\eta$ results in the increase in the thermal resistance to heat flow through the pipe wall. However, the effect of conduction through the wall and convection at the outer wall of the pipe is more pronounced on $\Theta_{w}$ than on $\Theta_{b}$ that is why there is higher temperature drop on the wall than in the fluid bulk. With respect to $B i$, the wall temperature decreases with increase in $B i$ for the case presented in Fig. $6\left(P e=5, k_{p f}\right.$ $=10$ and $\eta=0.5)$. Increase in $B i$ results in increase in 'heat transfer rate at the external wall side. This causes in a significant drop in the temperature of the pipe. Higher $B i$ leads to higher temperature gradient between the surfaces of the pipe, resulting in a substantial decrease in the wall temperature. As $B i$ increases, there is a decrease in the effect on the interface temperature. Fig. 7 shows the effect of $k_{p f}$ for the case when $B i=1, P e=5$ and $\eta=0.5$. The wall temperature generally decreases from the entrance to the exit of the flow due to the temperature gradient resulting from the $B i$ and $k_{p f}$. The effect of $k_{p f}$ is more significant on $\Theta_{w}$ than on $\Theta_{b}$.

The results of the effects of the three variables on the interficial heat flux are given in Figures 8 - 10 . The negative (heat flux) values are indications that heat is lost from the fluid to the environment via the wall interface. The rate of interficial heat flux is inversely proportional to $\eta$ hence the convective heat loss by the fluid. The thicker the pipe the higher the thermal resistance hence the lower the interficial heat loss (Fig. 8)

The relationship between $B i$ and $q_{w}^{\prime}$ is presented in Fig. 9. It shows that increased $B i$ result in an increase in heat loss from fluid to the environment. It can also be seen that the effect on $q_{w}^{\prime}$ reduces slightly with increasing $B i$. With respect to the effect of $k_{p f}$ on the heat transfer rate or heat loss, Fig. 10, shows that the rate of heat loss increases with $k_{p f}$. This is because an increase in $k_{p f}$ causes a decrease in the wall thermal resistance. Furthermore, the effect of $k_{p f}$ on $q_{w}^{\prime}$ decreases slightly as $k_{p f}$ increases.

\section{CONCLUSIONS}

In the present study, the analysis of the effects of two-dimensional wall conduction and fluid axial conduction for laminar flow in a thick-walled pipe subjected to convective boundary conditions of the third kind is presented. Two energy equations, one for the fluid and the other for the pipe, were solved using separation of variables method for the conjugate heat transfer problem. Results were simulated for pipe thickness ranging between 0.1 and 2.0, Biot number between 0.1 and 10.0 and the ratio of pipe wall-to-fluid thermal conductivity between 3.0 and 100.0 . The effects of three parameters (pipe wall thickness, Biot number and pipe wall-to-fluid thermal conductivity ratio) were investigated and the finding summarized as follows:

1). Bulk and wall temperatures and heat flux are sensitive to the three parameters under investigation.

2). The fluid bulk and wall temperatures decrease with decreasing pipe wall thickness $\eta$, increasing $B i$ number, and increasing $k_{p f}$.

3). An increase in $\eta$, leads to the convective heat loss becoming smaller while increase in both $B i$ and $k_{p f}$ lead to increased heat loss to the environment. This is because increase in wall thickness increases the thermal resistance to heat transfer between the fluid and the environment leading to a lower interfacial heat loss and a higher temperature profiles at the wall and fluid. On the other hand, increase in $B i$ and $k_{p f}$ correspond to increase in the convective heat loss resulting in a larger interfacial heat flux but lower temperature profiles in the wall and fluid.

4). All the parameters considered are very important at the thermal entry region and have effect on the thermal entrance length. However, with increase in pipe wall thickness, the thermal entrance length increases while it decreases with increase in both $B i$ and $k_{p f}$.

\section{ACKNOWLEDGEMENT}

The funding obtained from the NRF, TESP, University of Stellenbosch/ University of Pretoria, SANERI/SANEDI, CSIR, EEDSM Hub and NAC is acknowledged and duly appreciated. 


\section{REFERENCE}

[1] Guedes ROC, Ozisik MN. Conjugate turbulent heat transfer with axial conduction in wall and convection boundary conditions in a parallel - plate channel. Int J Heat Fluid Flow, 1992; 13: 322-8.

[2] Shah RK, London AL. Laminar flow forced convection in ducts. Academic Press, New York; 1978.

[3] Shah RK, Bhatti MS. Laminar convective heat transfer in ducts. In: Kakac S, Shah RK, Aung W, editors.

Handbook of single-phase convective heat transfer. John Wiley: New York; 1987.

[4] Vick B, Ozisik MN. Effects of axial conduction and convection boundary conditions in slug flow inside a circular tube. Trans ASME J Heat Transfer 1981; 103: 436-440.

[5] Vick B, Ozisik MN, Ullrich DF. Effects of axial conduction in laminar tube flow with convective boundaries. J Franklin Inst 1983; 316: 159-173.

[6] Lee SL, Hwang GJ. Finite element solution of low Peclet number fluid flow in round pipe with Cauchy boundary condition. The Canadian J Chem Eng 1981; 59: 760-765.

[7] Mori S, Sakakibara M, Tanimoto A. Steady heat transfer to laminar flow in a circular tube with conduction in tube wall. Heat Transfer Jap Res 1974; 3: 37-46.

[8] Mori S, Shinke T, Sakakibara M, Tanimoto A. Steady heat transfer to laminar flow between parallel plates with conduction in wall. Heat Transfer Jap Res 1976; 5: 17-25.

[9] Davis EJ, Gill NW. The effects of axial condution in the wall on heat transfer with laminar flow. Int J Heat Mass Transfer 1970; 13: 459-470.

[10] Faghri M, Sparrow EM. Simultaneous wall and fluid axial conduction in laminar pipe-flow heat transfer.

ASME J Heat Transfer 1980; 102: 58-63.

[11] Zariffeh EK, Soliman HM, Trupp AC. The combine effects of wall and fluid axial conduction on laminar heat transfer in circular tubes. J Heat Mass Transfer 1982; 4: 131-135.

[12] Campo A, Rangel R. Lumped system analysis for the simultaneous wall and fluid axial conduction in laminar pipe flow heat transfer. PhysicoChem Hydrodyn 1983; 4: 163-173.

[13] Pagliarini G. Effects of axial conduction in the wall and fluid on conjugate heat transfer in thick-walled circular tubes. Int Comm Heat Mass Transfer 1988; 15: 581-591.

[14] Barozzi GS, Pagliarini G. A method to solve conjugate heat transfer problems: the case of fully developed laminar flow in a pipe. ASME J Heat Transfer 1985; 107: 77-83.

[15] Campo A, Shuler C. Heat transfer in laminar flow through circular tubes accounting for two-dimensional wall conduction. Int J Heat Mass Transfer 1988; 31: 2251-2259.

[16] Bilir S. Laminar flow heat transfer in pipes including two- dimensional wall and fluid axial conduction. Int J Heat Mass Transfer 1995; 38 (9): 1619-1625.

[17] Chung SY, Sung HJ. Direct numerical simulation of turbulent concentric annular flow Part 2: Heat transfer. Int J Heat Fluid Flow 2003; 24: 399 - 411.

[18] Redjem-Saad L, Ould-Rouiss M, Lauriant G. Direct numerical simulation of turbulent heat transfer in pipe flows: Effect of Prandtl number. Int J Heat Fluid Flow 2007; 28: 847 - 861.

[19] Eshahani JA, Shahabi PB. Effect of non-uniform heating on entropy generation for the laminar developing pipe flow of a high Prandtl number fluid. Energy Conversion Management 2010; 51: 2087 - 2097.

[20] Tso CP, Sheela-Francisca J, Hung Y-M. Viscous dissipation effects of power-law fluid flow within parallel plates with constant heat fluxes. J Non-Newtonian Fluid 2010; 165: 625 - 630.

[21] Ates A, Danci S, Bilir S. Unsteady conjugated heat transfer in thick walled pipes involving two-dimensional wall and axial fluid conduction with uniform heat flux boundary condition. Int J Heat Mass Transfer 2010; 53: 5058 $-5064$

[22] Hajmohammadi MR, Pouzesh A, Poozesh S. Controlling the heat flux distribution by changing the thickness of heated wall. J Basic Appl Sci 2012; 2(7): 7270 - 7275.

[23] Al-Maliky RF. Force convection of laminar liquid flow inside pipe exerted to non-uniform heat flux. Int J

Therm. Technolo 2013; 3(3): 113 - 119.

[24] Zhang S-X, He Y-L, Lauriat G, Tao W-Q. Numerical studies of simultaneously developing laminar flow and heat transfer in microtubes with thickwall and constant outside wall temperature. Int J Heat Mass Transfer 2010; 53: 3977-3989.

[25] Guo Z-Y, Li Z-X. Size effect on single-phase channel flow and heat transfer at microscale. Int J Heat Fluid Flow 2003; 24: 284-298.

[26] Herwig H, Hausner O. Critical view on "new results in micro-fluid mechanism": an example. Int J Heat Mass Transfer 2003; 46: 935-937.

[27] Maranzana G, Perry I, Maillet D. Mini- and Micro-channels: influence of axial conduction in the walls. Int J Heat Mass Transfer 2004; 47: 3993-4004.

[28] Ozisik MN. Boundary value problems of heat conduction. Dover Phoenix ed. Dover Publication, Inc., New York; 1968. 